\title{
JESÚS MARÍA GONZÁLEZ GARCÍA: ABORTO TERAPÉUTICO Y DERECHO A ENTERRAR AL FETO: LECTURA CONSTITUCIONAL A LA LUZ DE UN CASO REAL ${ }^{1}$
}

\section{THERAPEUTIC ABORTION AND RIGHT TO BURY THE FETUS: CONSTITUTIONAL INTERPRETATION IN THE LIGHT OF A REAL CASE}

RESUMEN: Análisis de la STC 11/2016, en la que se otorga el amparo a una madre a la que se denegó el derecho a enterrar el feto, tras la práctica de un aborto voluntario. La sentencia entiende vulnerado el derecho a la intimidad personal y familiar (art. 18.1 CE), aunque se analiza también la posible vulneración del derecho a la libertad ideológica y de conciencia (art. 16.1 CE) y a la igualdad en la aplicación de la ley (art. $14 \mathrm{CE}$ ).

ABSTRACT: Analysis of the Constitutional Court Judgment n. 11/2016, which acknowledges the right of one mother to bury (cremation) her fetus, which was denied by the judge, after the practice of a therapeutic abortion. The decision declares the violation of the right to personal and family privacy (art. 18 of Sp. Const.), but the text studies as well the possible violation of the freedom of ideology, thought and conscience (art. 16.1) and of the right to equality in the law enforcement (art. 14).

PALABRAS CLAVE: Libertad ideológica y de conciencia, Derecho a la intimidad familiar, Derecho a la vida familiar, Igualdad ante la ley, Derecho al enterramiento.

KEY WORDS: Freedom of ideology, thought and conscience, Right to family privacy, Right to respect for private and family life, Equality in the law enforcement, Right to burial.

\section{PLANTEAMIENTO}

La Sentencia del Tribunal Constitucional (STC) 11/2016, de 1 de febrero (Sala primera ${ }^{2}$ ) otorgó el amparo a una madre a la que la autoridad judicial había negado el derecho a enterrar los restos de su hijo no nacido, tras haberle sido practicado un aborto terapéutico. La decisión, que tuvo cierto eco mediático, plantea muy interesantes cuestiones desde varios puntos de vista,

\footnotetext{
${ }^{1}$ Profesor Titular de Derecho Procesal de la Universidad Complutense. Acreditado para el Cuerpo de Catedráticos de Universidad.

${ }^{2}$ Ponente, Sr. Ollero Tassara.
} 
no sólo jurídico-constitucionales, y fue fruto de un intenso debate de fondo por parte de la Sala; así lo acredita el hecho de que contra ella se emitieron tres votos particulares, dos discrepantes (uno de ellos del Presidente del Tribunal, que incluso llega a sostener que la demanda debió haber sido inadmitida a trámite $^{3}$ ) y otro del propio ponente, concurrente con la parte dispositiva de la Sentencia, pero discrepante en cuanto a su motivación.

Reveladora de las dificultades para alcanzar una decisión mayoritaria en el caso es, precisamente, la exigua mayoría que la respalda. Formada la Sala en ese momento únicamente por cinco Magistrados ${ }^{4}$, el resultado final sólo obtuvo tres votos favorables, mayoría que incluso podría haber sido insuficiente de haber estado completa la Sala con los seis Magistrados previstos por el art. 7 de la Ley Orgánica 2/1979, del Tribunal Constitucional ${ }^{5}$ (LOTC). Con ese apoyo mayoritario no contó, paradójicamente, la fundamentación del fallo estimatorio, pues fueron más los Magistrados de la Sala que discreparon de la ratio decidendi de la sentencia que quienes le dieron su respaldo (dado tan sólo por dos de sus cinco integrantes). Un patente desacuerdo que no impidió otorgar el amparo constitucional en un procedimiento tal vez evitable de haber existido mayores dosis de sentido común por parte de los responsables sanitarios y de los órganos judiciales que denegaron la solicitud de entrega del feto. Nos encargamos en este trabajo de analizar las claves jurídicoconstitucionales de esta decisión. Mas cualquier análisis del fondo de la cuestión requiere, aun esquemáticamente, hacer un recordatorio de los hechos.

\section{ALGUNOS DETALLES DEL CASO}

\section{a) La denegación de la solicitud por la jurisdicción ordinaria}

La recurrente en amparo había conocido que el hijo que esperaba tenía malformaciones severas incompatibles con la vida (diagnóstico posteriormente confirmado por un hospital público y una clínica privada), tras practicársele la ecografía de las 20 semanas. De acuerdo con los datos aportados por la sentencia, el feto sufría polimalformaciones "con hallazgos sugestivos de cromosomopatía", que hacían improbable su viabilidad. Como consecuencia de

\footnotetext{
3 "En definitiva, por respetable y comprensible que pueda resultar la pretensión de la demandante, y por más que su solicitud pudiera encontrar conexión con otros preceptos constitucionales, la argumentación expuesta me lleva a concluir que la inexistencia de lesión de los derechos fundamentales invocados debió conducir en su momento a la inadmisión del recurso de amparo, y ahora en fase de sentencia, a su desestimación" (Voto Particular del Sr. Pérez de los Cobos y Orihuel, párrafo final).

${ }^{4}$ Al haber una vacante por el fallecimiento del Magistrado D. Luis Ortega Álvarez, quien sí formó Sala al tiempo de la admisión a trámite de la demanda de amparo.

${ }^{5}$ Considerando que, de haber empate en la votación, decide el voto de calidad del Presidente (art. 90.1 LOTC), quien, como hemos visto, fue contrario al otorgamiento del amparo.
} 
ello, se le practicó un aborto legal en el Hospital de Mendaro (Guipúzcoa), a las 22 semanas de gestación y cuando el feto pesaba sólo 362 gramos.

Según los antecedentes de la sentencia de amparo, tras la práctica del aborto, la recurrente solicitó del hospital los restos, con el fin de poder despedirse del feto con su pareja y proceder a su incineración. Los responsables del centro hospitalario, sin embargo, rechazaron la solicitud argumentando que, según su protocolo interno, los fetos de menos de 500 gramos y tiempo de gestación inferior a 180 días son considerados "resto quirúrgico" y no están sujetos a la normativa sobre sanidad mortuoria a efectos de las solicitudes de incineración o enterramiento; el feto no cumplía ninguna de las dos condiciones de edad y peso, por lo que se indicó a la solicitante que para accederse a su solicitud necesitaba la autorización del juez. Siguiendo las indicaciones, la demandante presentó un escrito en el Juzgado de Primera Instancia e Instrucción núm. 1 de Éibar (en cuya demarcación se encontraba el hospital, en funciones de guardia) en el que se solicitaba autorización judicial para la inscripción en el Registro Civil del feto, como requisito previo para la obtención de la preceptiva licencia de enterramiento e incineración.

Admitido el escrito, se tramitó como diligencias previas penales; pero, tras reconocer que en el aborto practicado no existía indicio alguno de criminalidad $^{6}$, el Juzgado rechazó la petición (Auto de 17 de octubre de 2013). La resolución judicial entendía que no era de aplicación el protocolo por el que se rige el hospital para estos casos, por no ser norma jurídica vinculante en el sentido del art. 1 del Código Civil, "y que ni el art. 45 de la Ley de 8 de junio de 1957, del Registro Civil, interpretado conforme al contexto y a la realidad social (art. 3 del Código Civil), ni la legislación en materia de sanidad mortuoria dictada a efectos de seguridad pública (Decreto 2263/1974, de 20 de julio, por el que se aprobó el Reglamento de policía sanitaria mortuoria, y el Decreto 202/2004, de 19 de octubre, de la Comunidad Autónoma del País Vasco, por el que se aprueba el Reglamento de sanidad mortuoria) prohíben en ningún caso la inscripción de los fetos que no alcanzan 180 días, y que no existe norma legal que recoge el dato del peso mínimo" (FD primero del Auto). Pese a ello, el órgano judicial consideró como presupuesto legal para la entrega del feto la aplicación de las normas del Registro civil sobre inscripción de no nacidos y decidió finalmente desestimar la solicitud previa ponderación de "las normas en conflicto", entendiendo, de la exigencia por art. 45 de la Ley de Registro Civil de un deber de inscripción de las criaturas de más de 180 días, una prohibición de la inscripción de aquellas que no alcanzasen esa edad (FD segundo del Auto).

Esta conclusión se alcanza aun constando al Juez un informe médico forense en el que se concluye que no hay ningún impedimento médico legal sanitario para acceder a la solicitud, y que no se prohíbe en la legislación sobre sanidad mortuoria la inscripción de criaturas abortivas de menos de 180 días.

\footnotetext{
${ }^{6}$ Al entenderse cumplido los requisitos del art. 15 b) de la Ley Orgánica 2/2010, de 3 de marzo, de salud sexual y reproductiva de la interrupción voluntaria del embarazo.
} 
El Auto denegatorio llegaba a afirmar también que no podían obviarse los protocolos establecidos "aunque no constituyan norma jurídica", y rechaza la petición, a pesar de que en otro caso resuelto por el mismo Juzgado se estimó una pretensión similar, pero porque se habían alegado razones religiosas, lo que no ocurría en el presente caso.

Antes de llegar al Tribunal Constitucional, la recurrente interpuso recurso de reforma contra el Auto, alegando que la solicitud inicial se formuló al amparo de los derechos fundamentales regulados en los arts. 16 (libertad ideológica, religiosa y de culto) y 18.1 (intimidad familiar) de la CE, como causa legal para autorizar la entrega del feto, pero el recurso fue desestimado por el Juzgado (Auto de 12 de noviembre de 2013) ${ }^{7}$. Según éste, era cierto que en otra ocasión había autorizado el enterramiento, pero era un caso diferente, pues se trataba de un aborto espontáneo de veintidós semanas y 440 gramos "lo que se aproxima en mayor medida tanto al art. 45 de la ley del registro civil como a los límites previstos en el protocolo" y, de otro lado, porque "en la propia comparecencia recogida a los padres en el juzgado de guardia se invocaba como motivo el ser musulmanes y el hecho de que esta religión prohíbe la incineración por lo que desean entrar al feto": se daba a entender, pues, como determinante de la denegación, a sensu contrario, que la solicitante no hubiera alegado razones religiosas, a diferencia de lo hecho en la solicitud atendida, que el propio Juzgado había puesto de relieve.

Apelada esta última resolución judicial, la Audiencia Provincial de Guipúzcoa (Sec. 3aㅡ) la confirmó en Auto de 23 de diciembre de 2013, que cerró la vía judicial previa al recurso de amparo. Para la Audiencia, resumidamente, toda la normativa implicada (el art. 45 de la Ley del Registro Civil, la legislación en materia de policía sanitaria mortuoria, el art. 7 de la Convención sobre los derechos del niño de 20 de noviembre de 1989 -que recoge el derecho del niño a la inscripción "inmediatamente después de su nacimiento"-, el art. 15 de la Ley Orgánica 2/2010 y el protocolo hospitalario), interpretada conjuntamente, implicaba que en este supuesto "no sea preceptiva la inscripción en el Legajo de criaturas abortivas, necesaria para expedir la licencia de enterramiento, ni su tratamiento como resto cadavérico": Entiende también que no pueden atenderse las resoluciones alegadas del Tribunal Europeo de Derechos Humanos, por referirse a un supuesto fáctico distinto.

\section{b) Un pequeño galimatías legal: inexistencia de norma directamente aplicable al caso}

\footnotetext{
${ }^{7}$ En el recurso se alegaba también que desde el derecho romano existen respuestas para acceder a la legítima petición de la demandante, como el ius sepulcrhi o derecho a enterrar a los fallecidos, incluyendo el feto expulsado sin vida o los restos humanos. Se citaba del mismo modo las SSTEDH, en los casos Hadri-Vionnet contra Suiza, Pannullo y Forte contra Francia y Elli Poluhas Dodsbo contra Suecia.
} 
Todo lo expuesto en el epígrafe anterior pone de manifiesto las consecuencias derivadas de la inexistencia de una previsión normativa que regule expresamente el caso controvertido y la confluencia de sistemas normativos; e, indirectamente, cómo contribuye a la seguridad jurídica la existencia de un régimen legal claro. Todo ello dio pie a un pequeño galimatías legal, iniciado por la primera negativa del centro sanitario en atender la solicitud de la recurrente al amparo de un protocolo interno (que, salvo error, no aparece en la lista de fuentes del Derecho del art. 1 del Código Civil), eludiendo así una responsabilidad que se hacía recaer en el juez; pero, al tiempo, generando un problema a la jurisdicción, continuado por la decisión de la madre de no impugnar en vía administrativa la negativa del hospital y, en lugar de ello (cierto es que siguiendo de buena fe la indicación dada en el hospital), de acudir al Juzgado de Primera Instancia e Instrucción; y culminado por éste al dar curso a la petición de la madre en forma de diligencias previas penales, en un asunto en el que no había atisbo de hecho de apariencia delictiva alguno.

A partir de ahí, entraron en juego dos complejas labores del jurista, la calificación de los hechos enjuiciados y la determinación de la norma aplicable al caso. Consecuencia de las cuales fue una decisión discutible, cuando menos, en el plano de la legalidad ordinaria. En efecto, el caso controvertido se situaba en una zona fronteriza, planteándose la duda de si le era de aplicación la normativa sobre sanidad mortuoria o, por el contrario, si lo era la legislación sobre el Registro civil; amén de las relativas a la interacción entre ambas, dado que el Juzgado consideraba como condición sine qua non para atender la pretensión de autorizar el enterramiento la previa inscripción registral.

El Reglamento de policía sanitaria mortuoria (aprobado por Decreto 2263/1974, de 20 de julio) ${ }^{8}$ no prohíbe la inscripción en el Registro civil de fetos de hasta 180 días de gestación, tal como el Juzgado puso de relieve en su primer Auto. De acuerdo con su art. 6.2, podían ser objeto de enterramiento o incineración $n^{9}$ los restos humanos "de entidad suficiente" procedentes de "abortos, mutilaciones y operaciones quirúrgicas, sin otro requisito, en el orden sanitario, que el certificado facultativo en que se acredite la causa y procedencia de tales restos". En forma parecida se expresa el art. 5 del Reglamento de sanidad mortuoria del País Vasco ${ }^{10}$, de acuerdo con cuyo art. 3 el aborto tiene la consideración de resto humano cuando posee "entidad suficiente", al igual que los procedentes de intervenciones quirúrgicas 0 amputaciones. Ello no bastó para atender la solicitud, dado que la Juez

\footnotetext{
${ }^{8}$ Norma dirigida a agilizar y simplificar los trámites en los transportes de cadáveres, tanto dentro del territorio nacional como para el extranjero, con objeto de que las familias no encuentren agravados los problemas que tienen que afrontar en tan tristes circunstancias, con impedimentos económicos y restricciones o formalidades onerosas, ante el incremento de "supuestos de deseo de los familiares del difunto de que los restos reposen definitivamente en localidad distinta de aquella donde se produce el fallecimiento" (así en su Preámbulo).

${ }^{9}$ La norma añade, como tercer posible destino final de los restos, la inmersión en alta mar.

${ }^{10}$ Aprobado por Decreto 202/2004, de 19 de octubre, del Gobierno Autónomo Vasco.
} 
entendió necesario el otorgamiento de la licencia de enterramiento, hecho condicionado a la previa inscripción de la muerte en el Registro Civil, y ésta a su vez a la inscripción del nacimiento. Entró en juego aquí, en consecuencia, la legislación sobre Registro civil, en concreto, el art. 45 de la Ley del Registro Civil de 1957"11: "Las personas obligadas a declarar o dar el parte de nacimiento están también obligadas a comunicar en la misma forma el alumbramiento de las criaturas abortivas de más de ciento ochenta días de vida fetal, aproximadamente."

Para resolver la controversia era necesario, en resumen, determinar si el feto era un "resto humano" o no, para lo cual había de darse contenido al concepto indeterminado de "entidad suficiente". Dependiendo de lo uno o de lo otro, nos encontraríamos ante un hecho inscribible en el Registro civil o ante un "resto quirúrgico" merecedor de idéntico tratamiento a cualquier otro resto obtenido, pero no del enterramiento. El Juzgado, con la ulterior corroboración de la Audiencia Provincial, entendió que, por sus características de peso y edad, el feto carecía de entidad suficiente, y lo hizo aplicando dos parámetros: primero, el protocolo interno del hospital, que establecía un peso mínimo de 500 gramos (requisito no exigido por la Ley del Registro Civil de 1957 ni por los Reglamentos de sanidad mortuoria), y que no alcanzaba el feto en el caso controvertido; segundo, el art. 45 de la Ley del Registro Civil, que impone el deber de comunicar al Registro Civil, para su inscripción, el alumbramiento de criaturas abortivas de más de 180 días de vida fetal. Ello, junto con el hecho de que la gestante no hubiera solicitado la licencia de enterramiento por razones religiosas (como con anterioridad hizo otra gestante de religión islámica, en pretensión acogida por la Juez), determinó el rechazo de la petición.

Esta prolija argumentación era discutible en el plano de la legalidad. Por un lado, como hemos dicho, no se puede otorgar fuerza de norma jurídica a un protocolo interno que ni siquiera posee fuerza vinculante para sus destinatarios. Por otro, los tribunales intervinientes dedujeron, de una norma que imponía el deber de inscripción de los fetos en ciertas condiciones, una norma prohibitiva de inscribir aquellos que no las reunieran (algo difícilmente compatible con el principio de legalidad). Y, por último, el órgano judicial entendía que la autorización sólo podía basarse, como hecho extraordinario, en la alegación de motivos religiosos, pero no, por ejemplo, en la invocación de la mera libertad ideológica de la madre gestante. Aquí es donde se plantea la controversia constitucional, en los términos que seguidamente se expone.

\section{RAZONES CONSTITUCIONALES PARA OTORGAR EL AMPARO: DEL DERECHO A LA LIBERTAD IDEOLÓGICA AL DERECHO A LA VIDA FAMILIAR}

\footnotetext{
${ }^{11}$ Que no se entiende derogado por la disposición derogatoria primera de la Ley 19/2015, de 13 de julio, del Registro Civil, al no oponerse a las normas contenidas en ésta última.
} 
La Sala primera del Tribunal Constitucional apreció que el recurso tenía especial trascendencia constitucional por plantearse un problema o afectar a una faceta de un derecho fundamental sobre el que no había doctrinal constitucional (vid. la STC 155/2009, FJ 2, a), y admitió a trámite la demanda de amparo. Tres fueron los derechos fundamentales cuya vulneración se denunciaba: el derecho a la libertad ideológica, religiosa y de culto (art. $16 \mathrm{CE}$ ), el derecho a la intimidad personal y familiar (art. 18.1 CE), el derecho a la igualdad en la aplicación de la ley (art. $14 \mathrm{CE}$ ). Alguno de los votos particulares niega la existencia de esa relevancia por la vía de cuestionar la existencia misma del derecho a enterrar, en el plano de la legalidad ordinaria, por el hecho de que no haya una norma que expresamente lo reconozca: a nuestro entender, esta tesis sólo es admisible de negarse el juego de los arts. 16.1 y 18.1 CE como norma directamente aplicable y legitimadora de las acciones humanas; y, a sensu contrario, impondría al legislador la carga diabólica de tener que legislar, negro sobre blanco, todas sus manifestaciones posibles, presentes o futuras, a fin de legitimar cualquier acción humana, no prohibida o contraria al orden público, que tuviera su base en el derecho a la intimidad o en el derecho a la libertad de conciencia o ideológica.

\section{a) La no viabilidad en el caso de la queja de desigualdad en la aplicación de la ley (art. 14 CE)}

De los tres motivos de amparo, la sentencia no se plantea que nos encontremos ante un caso de desigualdad con relevancia constitucional, por mucho que el informe del Ministerio Fiscal propusiera la estimación de recurso precisamente por vulneración del art. $14 \mathrm{CE}$. La recurrente argumentaba que el Juzgado de Éibar no había atendido su solicitud de enterramiento, aun a pesar de que reconocía haberlo hecho en otro caso en el que se habían aducido razones religiosas (se profesaba la religión musulmana, que exige el enterramiento, y no incineración, de los restos humanos), pero el Juzgado entendió insuficiente la apelación a la libertad ideológica o de conciencia, como título suficiente para autorizar la entrega del feto. Para la actora ello constituía un trato discriminatorio con relevancia constitucional. De los tres motivos de amparo, no obstante, éste era el menos verosímil de todos, conforme con la construcción constitucional del derecho de igualdad y a la no discriminación. Nos encontraríamos supuestamente ante una desigualdad en la aplicación de la ley (que es la que se produce cuando un tribunal da un diferente tratamiento a dos controversias idénticas que afectan a sujetos diferentes, sin justificarse razonablemente los motivos del cambio de jurisprudencia o de desigualdad de trato): lo que veda el derecho es el "cambio irreflexivo o arbitrario en la aplicación de una norma, lo cual equivale a mantener que, por el contrario, el cambio resulta legítimo cuando es razonado, razonable y con vocación de futuro, $[\ldots]$ con fundamento en razones jurídicas objetivas que excluyan todo significado de resolución ad personam o de ruptura ocasional en una línea que se venga manteniendo con normal uniformidad antes de la decisión divergente 
o se continúe con posterioridad"12, en una doctrina mantenida por el Tribunal Constitucional desde sus primeras sentencias.

Incluso sosteniendo la hipótesis de un cambio de criterio irreflexivo, no se puede obviar que los casos confrontados eran sustancialmente diferentes, pues no se trata de la aplicación diferente del derecho a la libertad religiosa en dos casos diversos por un mismo juez, sino de una disparidad de criterio en la aplicación de dos derechos fundamentales diferentes: el derecho a la libertad religiosa, en el primer caso, y el derecho a la libertad ideológica o de conciencia, en el analizado; por mucho que los dos se regulen en la misma norma constitucional (art. 16.1 CE). No puede por tanto haber desigualdad, puesto que los casos no son idénticos, y ello impide efectuar un adecuado juicio de contraste. Se debe recordar, además, que el art. $14 \mathrm{CE}$ no impide el cambio de criterio jurisprudencial o apartarse del precedente, sino que exige, de darse el caso, que se motiven las razones que lo justifica de acuerdo con los parámetros constitucionales de motivación ${ }^{13}$.

\section{b) El derecho a la vida familiar como fundamento del derecho a enterrar al hijo no nacido}

La demanda de amparo se estimó finalmente por vulneración del derecho a la intimidad familiar (del art. 18.1 CE). La ratio decidendi del fallo parte de la cita de precedentes del Tribunal Europeo de Derechos Humanos (TEDH), en relación con diferentes aspectos del derecho al enterramiento (ius sepulchri) y su integración en el derecho al respeto de la vida privada y familiar (art. 8 del CEDH). En efecto, el TEDH ha considerado contrario al Convenio Europeo la decisión de las autoridades rusas de no entregar para su enterramiento los cadáveres de los fallecidos en una operación antiterrorista, decisión amparada por la ley nacional pero adoptada sin evaluación individual de las circunstancias justificantes de la negativa ${ }^{14}$; el retraso excesivo en devolver el cuerpo a su familia tras la práctica de una autopsia para su enterramiento $^{15}$; el rechazo a entregar a la esposa la urna con las cenizas de su esposo) ${ }^{16}$; u otro en que se enterró al hijo nacido muerto tras parto prematuro en una fosa común sin informar a los padres, en donde se valora la existencia de un derecho del progenitor a asistir al enterramiento de su hijo

\footnotetext{
12 SSTC 105/2009, de 4 de mayo, FJ 4; y 178/2014, de 3 de noviembre, FJ 4, 179/2015, de 7 de septiembre, FJ 4, entre otras muchas.

${ }^{13}$ SSTC 63/1984, 49/1985, entre otras muchas.

${ }^{14}$ Asuntos Sabanchiyeva y otros c. Rusia (núm. 38450-2005, STEDH de 6 de junio de 2013), Maskhadova y otros c. Rusia (núm. 8071-2005, STEDH también de 6 de junio de 2013) y Abdulayeva c. Rusia (núm. 8552-2005, STEDH de 16 de enero de 2014).

15 Girard c. Francia (núm. 22590-2004, STEDH de 30 de junio de 2011) y Pannullo y Forte $c$. Francia (núm. 37794-1997, STEDH de 30 de enero de 2002).

${ }^{16}$ Asunto Elli Poluhas Dödsbo c. Suecia (núm. 61564-2000, STEDH de 17 de enero de 2006).
} 
acompañado de una ceremonia ${ }^{17}$; en el asunto Maric contra Croacia $^{18}$ se entendió vulnerado el art. 8 del CEDH porque el hospital que se hizo cargo de los restos de un niño nacido muerto en un parto a término no los enterró, sino que les dio el tratamiento de residuos clínicos, sin soporte en norma legal alguna (la ley nacional daba ese trato sólo a los fetos de menos de 22 semanas de gestación).

A partir de ahí, previo reconocimiento de que el derecho a la intimidad no es absoluto, sino que admite limitaciones, la STC 11/2016 (FJ 4, i. f.), en un looping argumental, concluye que la decisión recurrida vulnera el art. $18 \mathrm{CE}$, por no respetar las exigencias constitucionales sobre motivación de decisiones restrictivas del derecho fundamental. En concreto, por no contarse con cobertura de una norma legal, incumpliendo con ello el canon constitucional reforzado de motivación de resoluciones judiciales restrictivas de derechos fundamentales. El argumento es incontestable pues, siendo cierto que no hay norma aplicable directamente al caso, lo que finalmente determinó la denegación de la demanda fue una interpretación arbitraria del art. 45 de la Ley del Registro Civil de 1957, en términos de tutela judicial efectiva; la norma impone el deber de comunicar al Registro los abortos en ciertos casos, pero de ella no se puede deducir sin más, por aplicación de criterios hermenéuticos propios de las normas restrictivas de derechos, una prohibición a la inscripción de los abortos que no alcancen la edad fijada en la norma: no es conforme con el canon constitucional de motivación de sentencias (art. 24.1 CE) inferir una prohibición implícita de la aplicación extensiva de una norma jurídica, y ello lesiona, por tanto, el art. 18.1 CE.

Compartimos lo anterior en lo referente a la motivación de los Autos recurridos en amparo. Sin embargo, a nuestro entender, es más discutible relacionarlo con la vulneración del art. 18.1 CE en el modo en que hace la sentencia. Ese mismo razonamiento sobre la vulneración del canon reforzado de motivación sería aplicable, por ejemplo, para justificar la vulneración del derecho a la libertad ideológica (art. $16 \mathrm{CE}$ ), también invocado en la demanda, pero el fallo mayoritario opta por hacerlo al derecho a la intimidad familiar (art. $18 \mathrm{CE}$ ); y lo hace por la vía de vincular la petición de enterramiento del feto con el derecho al respeto a la vida privada y familiar del art. $8 \mathrm{CEDH}$. Mas, como ha declarado expresamente el Tribunal Constitucional, la CE "no reconoce un 'derecho a la vida familiar' en los mismos términos que el Tribunal Europeo de Derechos Humanos"19. Lo que el art. 18.1 CE protege es la "intimidad misma", pero no las "acciones privadas o íntimas de los hombres" (STC 89/2013, de 3 de junio, FJ 2); y aunque el espacio vital protegido por el "derecho a la vida familiar" (derivado de los arts. 8.1 CEDH y 7 de la Carta de derechos

\footnotetext{
${ }^{17}$ Asunto Hadri-Vionnet contra Suiza (núm. 55525-2000, STEDH de 14 de enero de 2008), invocada en la demanda de amparo.

${ }^{18}$ STEDH de 12 de junio de 2014, núm. 50132.

${ }^{19}$ SSTC 236/2007, de 7 de noviembre, FJ 11, y 186/2013/FJ 7.
} 
fundamentales de la Unión Europea), no carece de protección dentro de nuestro ordenamiento constitucional en "la configuración autónoma de las relaciones afectivas, familiares y de convivencia", es jurisprudencia constitucional reiterada que (STC 183/2013, FJ 6); aun así, el "derecho a la vida familiar" no es una de las dimensiones comprendidas en el derecho a la intimidad familiar ex art. 18.1 CE y su protección no puede exigirse a través del recurso de amparo (STC 18672013, de 4 de noviembre, FFJJ 6 y 7$)^{20}$. En otras palabras, es cierto que se vulnera el canon de motivación que impone una restricción a un derecho fundamental; mas, si se descarta que el derecho a la vida familiar forme parte del contenido del derecho que reconoce el art. 18.1 $\mathrm{CE}$, se echa en falta en la sentencia una mínima fundamentación de por qué y cómo, en estas condiciones, el derecho a despedirse del ser querido forma parte de esa esfera de intimidad que protege nuestra Constitución.

En eso mismo coinciden los dos votos discrepantes, cuando rechazan que el fallo estimatorio se pueda fundar en la vulneración del art. 18.1 CE; y compartimos la crítica hecha en uno de ellos en el sentido de que la sentencia omite cualquier consideración al derecho a la intimidad personal y familiar (que es el invocado) ${ }^{21}$, saltando de la referencia al derecho a la vida privada y familiar (del art. $8 \mathrm{CEDH}$ ) a apreciar que hubo vulneración del derecho por quiebra del canon de motivación, en los términos relatados.

\section{c) El derecho a la libertad ideológica como fundamento del derecho a enterrar al hijo no nacido}

Todo apunta a que la Sala estaba de acuerdo en no estimar el recurso de amparo por vulneración del derecho a la libertad ideológica y de conciencia (art. $16 \mathrm{CE}$ ); de forma sorprendente, no sólo porque es el principalmente invocado en la demanda y al que se refiere la motivación de los autos recurridos (pues, recordemos, el rechazo de la solicitud de enterramiento se basó, entre otras razones, en que este derecho no amparaba la petición, a diferencia del derecho a la libertad religiosa). La STC 11/2016 ha perdido una gran ocasión, por ello, para sentar doctrina sobre este concreto derecho fundamental, que protege las convicciones personales con independencia de su origen ideológico o religioso y se refiere "al conjunto de elaboraciones de la mente, esto es, al conjunto sistemático de representaciones, valores y creencias que refleja la forma en que los miembros de la formación social viven sus condiciones de existencia". Es, en resumen, una libertad que se ejerce "sin más limitación, en sus manifestaciones, que las necesarias para el mantenimiento del orden público protegido por la ley" (STC 46/2001, FJ 11).

\footnotetext{
${ }^{20}$ Sin perjuicio de que su reconocimiento, respeto y protección informará la práctica judicial (art. 53.3 CE), lo que supone que los jueces ordinarios han de tenerlos especialmente presentes al ejercer su potestad (STC 186/2013, de 4 de noviembre, FJ 7).

${ }^{21}$ Nos referimos al de la Magistrada Roca Trías, punto 3, argumentado in extenso.
} 
Compartimos en este punto las críticas del voto particular concurrente, en el sentido de que el Tribunal Constitucional ha tenido una magnífica ocasión para para establecer que el derecho a la libertad de conciencia, en los términos señalados, debe equipararse al derecho a la libertad religiosa, pues las dos son manifestación de la libertad de conciencia del individuo, con independencia de que las convicciones personales se basen en razones de origen religioso o no. Estas convicciones (que en el caso se proyectaban en la idea de la recurrente de que los restos del hijo no nacido, aun en las condiciones expuestas, merecen ser enterrados o incinerados, facilitándose una adecuada despedida por parte de sus padres), deben ser respetados cuando ello no afecte al orden público y no haya norma legal que lo prohíba, únicos límites aceptados por el art. 16.1 CE. En un derecho que, como la demanda de amparo recordaba, con acierto, es, junto con el derecho a la vida, es soporte troncal de todos los demás (STC 53/1985, de 11 de abril), y reconocido en los instrumentos internacionales sobre derechos humanos ${ }^{22}$.

\section{CONCLUSIÓN: UNA OPORTUNIDAD FALLIDA DE SENTAR DOCTRINA CONSTITUCIONAL SOBRE EL DERECHO A LA LIBERTAD IDEOLÓGICA Y DE CONCIENCIA}

Fácil habría sido la solución del caso de haberse planteado la estimación de la demanda por este último motivo y con ello se habría podido cumplir de forma plena la finalidad querida del recurso de amparo, tras su reforma por la Ley Orgánica 6/2007, dando prevalencia a su función como instrumento para la creación, aclaración o modificación de la doctrina sobre derechos fundamentales (protección del ius consitutionis).

La libertad ideológica es reconocida por la doctrina constitucional como fundamento mismo del orden político y la paz social. Sin ella "no serían posibles los valores superiores de nuestro ordenamiento jurídico que se propugnan en el art. 1.1 de la misma para constituir el Estado social y democrático de derecho que en dicho precepto se instaura"23. Es una manifestación concreta de la libertad abstracta y genérica a que se refiere el art. 1.1 CE, y fundamento "de otras libertades y derechos fundamentales", con los que colinda y de los que es soporte ${ }^{24}$, un derecho que pertenece a la persona en cuanto tal", imprescindible para la garantía de la dignidad humana (art. 10.1 CE), "fundamento del orden político español"25 junto con el derecho a la vida, a la integridad física y moral, a la intimidad y el derecho a la tutela

\footnotetext{
22 EI TEDH lo define como uno de los logros o fundamento de las sociedades democráticas" (SSTEDH de 20 de agosto de 1994, y 25 de mayo de 1993).

${ }^{23}$ SSTC 20/1990, de 15 de febrero, FJ 3; 177/2015, de 22 de junio, FJ 5.

${ }^{24}$ STC 20/1990, de 15 de febrero, FJ 4; STC 136/1999, de 20 de julio, FJ 13.

${ }^{25}$ SSTC 107/1984, de 23 de noviembre, FJ 3; 99/1985, de 30 de septiembre, FJ 2; y 130/1995, de 11 de septiembre, FJ 2.
} 
judicial efectiva ${ }^{26}$. No agota su contenido en la libertad del individuo para tener una concepción personal del mundo, en un plano meramente subjetivo o privado, pues se extiende también al derecho a actuar libremente con arreglo a su personal cosmovisión, se funde esta en razones de trascendencia religiosa o no. No es una mera libertad interior de tener ideas, sino que su contenido esencial incluye también una dimensión externa de libertad de acción frente a terceros según las propias convicciones. Según la STC 177/2015, de 22 de julio, FJ 5, la libertad ideológica "[c]omprende, además, una dimensión externa de agere licere, con arreglo a las propias ideas sin sufrir por ello sanción o demérito ni padecer la compulsión o la injerencia de los poderes públicos" (en este mismo sentido, vid. la STS 137/1990, de 19 de julio, FJ 8); y sus manifestaciones externas no se circunscriben a las orales o escritas, sino que incluyen también la adopción de actitudes y conductas que no dejan de ser actos de ejercicio de esta libertad por la circunstancia de que fácilmente se solapen con otros derechos fundamentales ${ }^{27}$.

Por todo ello, como decimos, el caso resuelto por la STC 11/2016 encajaba, perfectamente en el ámbito de este derecho fundamental, sin las dificultades puestas de relieve para fundarse en otros derechos fundamentales. En lugar de ello, se optó, desacertadamente a nuestro entender, por basar la estimación del recurso en la vulneración de un derecho que, de acuerdo con la doctrina mayoritaria del Tribunal Constitucional, no entra dentro del contenido esencial del precepto que se considera vulnerado (art. 18.1 CE); abriéndose con ello una puerta a la incertidumbre para futuras decisiones de amparo.

\section{BIBLIOGRAFÍA CITADA:}

FRAILE ORTIZ, M., "El derecho a despedirse ante el Tribunal Constitucional", Sepín, junio de 2016, Referencia: SP/DOCT/20453.

GONZÁLEZ RIVAS, J. J., La interpretación de la Constitución por el Tribunal Constitucional, Civitas Thompson Reuters, 2011.

MIERES MIERES, L. J., Intimidad personal y familiar: prontuario de jurisprudencia constitucional, Cizur Menor (Navarra), Aranzadi, 2002.

MOLINER VICENTE, C., "Intimidad familiar y vida familiar La mayor amplitud del concepto "vida familiar" sobre el de "intimidad familiar" de nuestra Constitución", Diario La Ley, №. 8316 (22 de mayo de 2014)

\footnotetext{
${ }^{26}$ STC 236/2007, de 7 de noviembre, FJ 3.

${ }^{27}$ ATC 1227/1988, de 7 de noviembre, FJ 2.
} 
SALES I JARDÍ, M., La vida familiar en la jurisprudencia del Tribunal Europeo de Derechos Humanos: una interpretación constructiva, Barcelona, Bosch, 2015.

XIOL RíOS, J. A., "La libertad ideológica o libertad de conciencia", La libertad ideológica. VI Jornadas de la Asociación de Letrados del Tribunal Constitucional, Centro de Estudio políticos y Constitucionales, 2001, pp. 11-80. 